\title{
Desafios na Resolução de Conflitos no ambiente escolar: práticas restaurativas na educação
}

\author{
Cristiane Vilhena de Souza \\ Universidade Estadual do Ceará - UECE \\ Kátia Paulino dos Santos \\ Universidade Estadual do Ceará - UECE
}

\begin{abstract}
Resumo
A escola tem sido palco de conflitos e violência e o alvo são as crianças e adolescentes, que em algum momento são vítimas e em outros momentos são infratores. Tais acontecimentos despertam o interesse em compreender estes fenômenos de forma ampla e suas consequências no dia-a-dia das escolas. Este estudo investigou o funcionamento de uma política pública voltada para a resolução de conflitos no ambiente escolar. Baseada em uma metodologia qualitativa e na técnica do estudo de caso, foi analisada a criação do Núcleo de Práticas Restaurativas (NPR) na Escola E. José Ribamar Pestana, localizada no município de Santana/AP. Sua clientela apresenta diferentes níveis de risco social, refletindo no ambiente educacional ações violentas. Este núcleo objetiva promover a cultura de paz, através da mediação de conflitos e da realização de atividades preventivas, utilizando a metodologia do Círculo Restaurativo e da Comunicação Não-Violenta. Verificou-se que, apesar de recémimplantado, vem provocando mudanças significativas na comunidade escolar e reduziu o número de casos de violência no ambiente escolar.
\end{abstract}

Palavra-chave conflitos; violência; práticas restaurativas; políticas educacionais.

\begin{abstract}
The school has been the scene of conflict and violence and the target is children and adolescents, who at some point are victims and at other times are violators. Such events arouse interest in understanding these phenomena in a broad way and their consequences in the daily life of schools. This study investigated the functioning of a public policy aimed at conflict resolution in the school environment. Based on a qualitative methodology and case study technique, the creation of the Restorative Practice Center (NPR) at the E. José Ribamar Pestana School, located in Santana / AP, was analyzed. Its clients have different levels of social risk, reflecting violent actions in the educational environment. This nucleus aims to promote a culture of peace through conflict mediation and preventive activities, using the methodology of the Restorative Circle and Nonviolent Communication. Although
\end{abstract}


newly implemented, it has been causing significant changes in the school community and has reduced the number of cases of violence in the school environment.

Key-word conflict and violence at school; restorative practices; policies educational.

\section{Introdução}

O dia-a-dia das instituições escolares, a partir de meados da década de 80, começou a passar por uma transição, no que diz respeito ao fenômeno da violência no âmbito escolar. Desde então, estabeleceu-se situações não antes vivenciadas por ela, comprometendo seu papel socializador, exigindo que a Escola tivesse uma outra postura, de tal forma que não havia mais espaço neste ambiente para métodos tradicionais, dentre eles, as punições, portanto seria necessário um novo modelo que privilegie a restauração das relações sociais, a reparação do dano e a prevenção.

Surge a necessidade de a escola lançar mão de ferramentas que possam lhe ajudar a proporcionar um ambiente mais adequado ao desenvolvimento intelectual dos alunos. Desse modo, utilizar as ferramentas das práticas restaurativas, representa uma nova alternativa de prevenção e resolução de conflitos no âmbito escolar. Uma oportunidade de perceber que existem outras maneiras de esclarecer possíveis problemas, pois não busca inocentes, culpados, ganhadores ou perdedores, mas busca alternativas criativas na solução de impasses, contribuindo para que escola possa prevenir a violência e a criminalidade através da promoção de uma cultura de paz.

No Estado do Amapá, uma parceria realizada entre Tribunal de Justiça, Ministério Público e Governo do Estado do Amapá, proporcionou o surgimento do projeto "Escola Restaurativa: promovendo uma cultura de paz nas escolas", e que posteriormente, culminaria na implantação dos núcleos nas escolas onde o índice de conflito e violência escolar eram maiores, registros identificados através do policiamento escolar e Secretaria de Estado da Educação. Desta parceria, foi criada a Lei 2.282 de 29 de dezembro de 2017, que dispõe sobre a criação do Programa Educação para a Paz no Estado do Amapá, com o objetivo de promover a cultura de paz, prevenção da violência e a melhoria da convivência nas unidades educacionais, por meio de um conjunto de ações articuladas e transversais.

Observa-se que as ações resultaram na política pública estabelecida pela Lei 2.282, de 29 de dezembro de 2017, ou seja, é uma ação recente. Daí explica-se o porquê de implementar as práticas da Justiça Restaurativa na educação, pois é um método complementar de resolução de conflitos, com base numa lógica de responsabilização. Nesse sentido este artigo possui como objetivo central investigar a aplicabilidade e os resultados das práticas restaurativas na mediação de conflitos em uma escola pública localizada em uma área periférica da cidade de Santana-AP, neste caso a Escola Estadual José Ribamar Pestana.

Para tanto, foi necessário discorrer sobre o aporte teórico das políticas públicas e da justiça restaurativa e sua aplicabilidade na educação; evidenciar os conflitos e a violência no âmbito escolar e suas implicações na formação da criança e do adolescente; dissertar sobre a inserção das práticas restaurativas no ambiente Escolar no auxílio a resolução de conflitos, evidenciando as contribuições, avanços e entraves quanto a aplicabilidade da política pública estabelecida para promoção da cultura de paz no Estado do Amapá; por fim demonstrar os resultados e desafios de inserção das Práticas Restaurativas no processo de resolução de conflitos no ambiente da Escola Estadual José Ribamar Pestana. 
Este trabalho está estruturado em quatro partes. Na primeira e segunda parte, foi desenvolvida uma visão de como os conflitos e a violência no ambiente escolar implicam na formação da criança e do adolescente, destacando os instrumentos e instituições que dão apoio a redução dos conflitos e da violência na escola.

$\mathrm{Na}$ terceira parte é discutido como as práticas restaurativas foram sendo introduzidas e desenvolvidas no ambiente escolar, demonstrando experiências e como elas atuam. E a quarta parte é o resultado da pesquisa de campo desenvolvida na E. E. José Ribamar Pestana, onde foi trabalhada desde a parte histórico-contextual da inserção da escola no cenário da cidade até a visão dos envolvidos nas práticas restaurativas dentro do ambiente desta instituição escolar, onde foi percebido que, apesar de recente, a implantação do Núcleo de Prática Restaurativa - NPR se tornou parte integrante da realidade da escola e vem mudando, mesmo que ainda de forma lenta, a realidade da escola.

\section{Metodologia da pesquisa}

Com relação aos procedimentos técnicos, a pesquisa trata de um estudo de caso, já que de acordo com Yin (2015, p. 04) esta forma permite compreender de uma forma holística e de mundo real os fenômenos individuais, grupais, organizacionais, sociais, políticos e relacionados. Este estudo tem como propósito um estudo exploratório, pois sua finalidade foi de proporcionar mais informações sobre o assunto investigado, além de proporcionar um planejamento flexível, o que permite o estudo do tema sob diversos ângulos e aspectos, como levantamento bibliográfico; entrevistas com pessoas que tiveram experiências práticas com o problema pesquisado e análise de exemplos que estimulem a compreensão do objeto estudado, de acordo com Prodanov e Freitas (2013). Neste caso, investigar a aplicabilidade e resultados das práticas restaurativas na mediação de conflitos no âmbito da Escola Estadual José Ribamar Pestana.

Com relação aos procedimentos técnicos, utilizou-se entrevista semiestruturada, que teve como sujeitos a gestora escolar, um (01) integrante da coordenação pedagógica, dez (10) professores, dez (10) alunos do ensino fundamental e médio, (05) pais, (02) membros do Ministério Público que atuam no Núcleo de Práticas de Resolução de Conflitos e 03 (três) Técnicos da Secretaria de Estado da Educação que acompanham o processo de implantação das Práticas Restaurativas nas Escolas em um processo de investigação que iniciou em 2016 e foi concluído em 2018, onde foram entrevistados como forma de captar de que forma as PR interferiram na vida da escola.

Utilizou-se também a técnica de observação não participante in loco para verificação da aplicação da metodologia das práticas restaurativas no ambiente escolar, pois permite conseguir informações e utiliza os sentidos na obtenção de determinados aspectos da realidade. Esta técnica não consiste apenas em ver e ouvir, mas também de examinar fatos ou ferramentas que se deseja estudar, ajudando a identifica e a obter provas a respeito dos objetivos. Quanto a interpretação dos dados pós-coleta, os mesmos foram interpretados, transcritos e tabulados, utilizando quadros e, ao final, foi realizado um relatório descritivo presente nesta parte da dissertação, relatando as etapas de desenvolvimento da pesquisa, descrevendo os resultados e fazendo conversações entre os dados coletados e o objeto pesquisado. 


\section{Conflitos e violência no ambiente escolar e suas implicações na formação da criança e do adolescente}

De acordo com a pesquisa do Instituto de Pesquisa Econômica Aplicada - IPEA (2018), os dados demonstram que houve um aumento na quantidade de jovens assassinados, entre anos de 2006 e 2016, em vinte Unidades Federativas do Brasil, onde o Acre $(+84,8 \%)$ e o Amapá $(+41,2 \%)$, se destacam com os maiores índices. Este dado é bastante significativo e evidencia a possibilidade de não terem sido adotadas medidas que pudessem sanar este problema, dentre elas políticas públicas de combate à violência, o que decorre a urgência de se tratar este problema com a devida importância, pois no Norte estes dados vêm aumentando numa incômoda aceleração.

Ao analisar estes conceitos, Ceccon et al. (2010) discorre que os conflitos são originários das diferenças, uma vez que os seres humanos são diferentes uns dos outros. Evidencia-se que os conflitos existem dentro de nós, por razões e emoções diferentes - e por vezes contraditórias - que habitam em cada ser humano. Na escola esses conflitos ocorrem com maior frequência entre docentes, entre alunos e docentes, entre alunos, entre pais, docentes e gestores.

Quanto à violência Eyng, Gisi e Ens (2009) discorre que se apresenta na vida cotidiana, como uma ameaça diária à integridade física, psíquica e da dignidade humana, sendo que as diferentes manifestações das violências no âmbito escolar vêm comprometendo ainda mais a qualidade da educação no contexto da escola pública brasileira. Esta é uma realidade que vem se percebendo em muitas escolas pelo pais1.

Já são percebidas muitas iniciativas de resoluções de conflitos e violência escolar no Brasil, e os estudos de Evans e Vaandering (2018) mostram que, nos últimos vinte anos, surgiram políticas públicas de redução da violência no âmbito escolar e que elas têm se originado, sobretudo, nas esferas estadual e municipal. Apesar de demostrar que algumas iniciativas são por vezes fragmentadas e descontinuas, já existe um considerável acumulo de experiências dessas políticas que demandam estudos sistemáticos para avaliar sua eficácia e proporcionar elementos para formulação de novas orientações.

Destacam-se aqui algumas políticas, a exemplo a Rede, que segundo, Nunes (2018) é uma forma de organização entre pessoas ou instituições, que buscam, de maneira horizontal, cooperar entre si, em torno de objetivos específicos. Segundo ele, esta política de atendimento prevê: ações articuladas e fortalecidas entre o sistema de garantias e direitos da criança e do adolescente.

Os operadores do direito, como o sistema de Justiça, o Ministério Público, as Defensorias Públicas e os Juizados Especiais da Infância, são Instituições que asseguram o direito, que acionadas pela escola ou não, são agentes que podem contribuir com a mudança da rotina na escola e que também fazem parte da REDE e conta, também, os Objetivos de Desenvolvimento Sustentável - ODS, que é um chamado universal para garantir que todas

\footnotetext{
1 Charlot (2008) aponta que é necessário fazer uma distinção entre a violência na escola, a violência à escola e a violência da escola: A primeira é aquela que se produz dentro do espaço escolar, sem estar ligada à sua natureza e as atividades da instituição escolar, ou seja, a escola é o espaço onde culminou a violência que começou fora daquele ambiente; A segunda, está ligada à natureza e às atividades a instituição escolar e se manifesta pelos problemas internos característicos da deficiência estrutural e educacional. Isto ocorre quando os alunos batem e insultam os professores, quando surgem relações pautadas pelo abuso de poder e assédio moral, quando provocam incêndios na escola, onde eles visam diretamente a instituição e aqueles que a representam; Por fim, a violência da escola, que representa uma violência institucional e simbólica que surge por meio da rebeldia e dos atos de vandalismo, onde os alunos se manifestam através da maneira como a instituição e seus agentes os tratam.
} 
as pessoas tenham paz e prosperidade. 0 objetivo 16, intitulado "paz, justiça e instituições eficazes", retrata muito bem isso. E é neste cenário, que algumas iniciativas emergem na tentativa de diminuir e prevenir a violência e os litígios nas escolas, trazendo resultados positivos.

\section{Práticas restaurativas no ambiente escolar: avanços e desafios no Brasil}

De acordo com Arlé (2018), a justiça restaurativa é uma prática, ou seja, é um conjunto de práticas restaurativas em busca de uma teoria que visa promover entre os protagonistas dos diferentes conflitos, iniciativas de solidariedade, diálogo e, de forma consensual, planos de ação reconciliadores. Essa visão ampliada de referências e elementos caracterizadores da justiça restaurativa é que levam a outros espaços além da justiça, como a escola e a comunidade.

Costello, Wachtel e Wachtel (2012) salientam que as práticas restaurativas não são um sistema único de mudança para todas as escolas. Cada escola deve desenvolver uma visão única do que quer conquistar, mas com a certeza e o reconhecimento de que algo precisa mudar, para tanto, se faz necessário restaurar o lugar da escola na sociedade, empoderando-a para tratar, de maneira mais apropriada os conflitos que forem emergindo.

No Brasil, a primeira metodologia utilizada foi a dos círculos restaurativos que é uma metodologia das práticas restaurativas, baseados em princípios de comunicação não violenta, com formato conversacional de conferência. 0 processo se dá com sequência que se inicia com o foco no relato, na escuta ativa e no compartilhamento das emoções e dos envolvidos diretos, para em seguida incluir os demais participantes indiretamente envolvidos ou suportes, com o objetivo de promover o diálogo, perceber a dimensão dos danos e atendimentos as necessidades desse ato ofensivo, bem como, democratizam o conhecimento e implementam a integração (AMSTUTZ; MULLET, 2018).

Para conseguir alcançar esses objetivos das PRE é necessário refletir quanto aos avanços dessa proposta e quais os desafios que são encontrados dentro do ambiente escolar para conseguir coloca-las em prática, e pode-se destacar como um avanço a vontade que Justiça e educação manifestaram de unir forças para sensibilizar e chamar a atenção para outras formas de resolução de conflitos que atingem crianças, jovens e adultos em escolas e comunidades, almejando a partir dessas parcerias a construção coletiva da cultura de paz nos mais diversos contextos institucionais e da criação de condições de garantia dos direitos das crianças e adolescentes e suas famílias no contexto brasileiro. Um fator que implica na implementação dessas práticas no Brasil é que, no âmbito criminal ou educacional, não estão previstas de forma específica em nenhuma lei, salvo a Resolução 125/2010 do CNJ e o Protocolo de cooperação para a difusão da Justiça Restaurativa.

Santana (2011) relata que o fato das práticas restaurativas não estarem contempladas nos documentos que norteiam a prática pedagógica da escola, acabam se tornando um problema, ou seja, um empecilho para que se implemente de fato esta prática; bem como toda a comunidade escolar ter conhecimento e formação para atuar com a metodologia das práticas restaurativas.

Portanto, os desafios ainda existem e podem ser superados no decorrer deste processo, dentre eles destacam-se: o voluntariado, a cultura punitiva, a rotatividade dos professores, a boa vontade de educadores em querer mudar e aprender, a falta de conhecimento dos segmentos da comunidade das práticas restaurativas, a divulgação dos 
resultados obtidos através dos círculos restaurativos e os valores norteadores das práticas restaurativas e vencendo estes desafios a escola encontrará formas criativas e sustentáveis de viabilizar e perpetuar as práticas restaurativas para resolver conflitos e prevenir a violência.

\section{Resolução de conflitos no ambiente escolar: estudo de caso na Escola Estadual José Ribamar Pestana - Santana - Amapá - Brasil}

Este artigo apresenta objetivo central investigar a aplicabilidade e resultados das práticas restaurativas na mediação de conflitos no ambiente escolar. Para tanto, foi realizado uma análise sobre a inserção das práticas restaurativas no ambiente escolar no auxílio à resolução de conflitos, com ênfase nas contribuições, avanços e entraves quanto a aplicabilidade da política pública estabelecida para promoção da cultura de paz no Estado do Amapá, demonstrando os resultados a partir da inserção das Práticas Restaurativas no processo de resolução de conflitos no ambiente da Escola Estadual José Ribamar Pestana, localizada em uma área periférica do município de Santana-AP, que atende a mais de 1000 alunos, nas modalidades de Ensino fundamental II, Ensino Médio, EJA fundamental e Médio, oriundos de diferentes bairros e com tipos de desenvolvimento e formas de interação social, além de amplas áreas de risco social e que registram várias formas de violência que acabam por reverberar no seio da escola. Violência e é evidente que as discussões não se baseiam apenas nos tópicos relacionados à violência, pois uma das propostas de discussão surge da proposição das comunidades para os mais variados problemas que surgem.

\section{Resultados e discussões}

Com base nas observações in loco e na conversa com a equipe gestora, com a equipe do Núcleo de Práticas Restaurativas e alguns professores foi possível obter informações quanto a aplicabilidade das práticas restaurativas e as metodologias adotadas na escola, portanto, o ano de 2016 foi determinante para que a escola fosse em busca de parcerias e apoio para solucionar os conflitos e a violência que estava ocorrendo dentro da escola e no seu entorno. Oficializou-se ao MP a realidade e solicitaram que fosse implantado um núcleo de práticas restaurativas na escola, sendo que o mesmo atendeu capacitando a escola como um todo e apresentou o trabalho em rede que é utilizado para a proteção da criança e do adolescente.

O Núcleo de Práticas Restaurativas foi implantado, com o intuito de buscar uma aproximação entre os pais, gestores, professores e alunos, a fim de estabelecer formas diversas de resolução pacífica de conflitos, baseados nos conceitos centrais da Justiça Restaurativa e da mediação de conflitos, estimulando, dessa forma, a incorporação dessas práticas nas relações de contexto escolar, desconstruindo, assim, uma cultura de violência e, em seguida, construindo uma cultura de paz.

Através da visita in loco a Instituição Pestana, foi possível aplicar as entrevistas ao gestor, coordenador pedagógico e professores, além de conversas para detalhar mais informações sobre o assunto. A gestão e a coordenação pedagógica relataram que há evidencias positivas das PR na escola, pois busca-se solucionar os conflitos numa perspectiva restaurativa e não mais de forma punitiva, informação também confirmada através do livro de ocorrências do turno da tarde, onde foi observado que o número de registro de ofensas a colegas, desrespeito ao professor, desrespeito as regras da escola 
diminuiu. Apesar de alguns pequenos entraves, entende-se que o conflito faz parte da vida das pessoas e em se tratando de escola, as ações devem ser construídas coletivamente para poder transformar o espaço da escola numa cultura de paz.

Quanto aos professores entrevistados, afirmaram que os resultados são bastante positivos na busca por soluções aos fatos observados na escola, e em suas opiniões após a implantação esses conflitos e casos de violência diminuíram. Ficou demonstrado também que melhorou o trabalho em equipe, bem como o relacionamento interpessoal dos alunos, comprometimento da equipe que coordena o trabalho, melhoria no relacionamento dos funcionários com os alunos, utilização do diálogo para resolver conflitos.

Quanto aos entraves foi destacado a pouca atenção por parte da família dos alunos envolvidos em problemas sociais graves, o que não permite em que haja mais círculos com a presença da família. Outra situação é que muitos professores não aceitam ou não conhecem as práticas. No que se refere aos desafios encontrados, inserir a família e a comunidade escolar no processo de resolução de conflitos através das práticas restaurativas ainda é necessário, conscientizando do processo das práticas na construção do processo social cidadã, além da intensificação das parcerias com o poder público.

Por fim, buscou-se saber quais resultados alcançados quando a família se envolve no processo de resolução de conflitos, destacou-se que são satisfatórios, o aluno demonstra melhorias na escola, mas ainda deve insistir para que a família participe e tenha melhores resultado, pois melhora o diálogo e atenção para com os filhos, o que torna um desafio para a escola, além da falta de compreensão que as pessoas têm das ações da proposta.

Ao ouvir a família para identificar seu conhecimento e avaliação quanto às práticas restaurativas, foi relatado que houve mudanças na escola, destacando a maneira de acolher a família, pois ela tem sido mais ouvida, existe diálogo com a família e com o aluno. Neste sentido, a escola passou a ter mais credibilidade com a comunidade, com os professores, levando a diminuir o índice de conflitos e de violência, pois havia muitas mutilações.

Segundo eles, os principais entraves ainda são com os pais que não frequentam a escola, pois aparecem somente na matrícula. Estes são resistentes a mudanças e os desafios perpassam ainda em fazer com que as famílias que ainda não conhecem as Práticas Restaurativas participem das atividades da escola, para que conheçam e aceitem essa nova metodologia.

Dos alunos entrevistados, disseram que após a implantação das PR, os casos de indisciplina na escola diminuíram consideravelmente e destacaram que houve melhoria nas relações entre eles e com os professores a partir de uma perspectiva dialógica e de busca do outro, o comportamento melhorou e isto acarreta na redução do número de conflitos e na violência no espaço escolar. Na opinião deles, o que poderia melhorar na escola em relação à resolução de conflitos, seria ter uma sala para atendimento, intensificar o trabalho com as PR e mais diálogo ainda entre os membros da comunidade escolar.

Para o Ministério Público as práticas restaurativas surtiram um efeito positivo, pois foi criada a Lei 2282 de 29 de dezembro de 2017, que dispõe sobre a criação do Programa Educação para a Paz no Estado do Amapá, com o objetivo de promover a cultura de paz, prevenção da violência e a melhoria da convivência nas unidades educacionais, por meio de um conjunto de ações articuladas e transversais, além da criação de uma ferramenta online que permite monitorar a violência nas escolas. 
A entrevista a Promotoria de Santana - MP demonstrou que as dificuldades para implementa-la está na rotatividade frequente de servidores na coordenação do Programa da Secretaria de Educação do Estado (E-Paz); a ausência de normatização específica, por parte da Secretaria de Estado da Educação, a disponibilidade de professores sem perder suas gratificações por estarem fora da sala de aula formalmente e; o apoio integral do gestor escolar; bem como resistência quanto à mudança de paradigma para lidar com os conflitos escolares (mudar do modelo punitivo para o restaurativo); dificuldade em disponibilizar tempo no calendário escolar para realização da formação com todos os funcionários da escola. Entretanto, houve alguns avanços que podem ser destacados: redução da evasão escolar; o aumento do índice do IDEB, comprovando a melhora no aprendizado; aumento na procura de vagas nas escolas que trabalham com a Pedagogia Restaurativa; além da diminuição da violência e; aproximação dos vínculos de afeto entre membros das famílias.

Com relação a entrevista realizada com a representante da Secretaria de Educação, especificamente a coordenação do E-Paz, foi abordado quanto a percepção do projeto de práticas restaurativas nas escolas e destacou que é visto como uma mudança de paradigma nos relacionamentos, e ajuda a construir uma cultura de paz. Entretanto, ainda existe desafios para sua implementação, dentre eles, sensibilizar os gestores e equipe pedagógica da escola, bem como tornar a sala de aula um espaço de relacionamentos saudáveis e consolidar os núcleos de práticas restaurativas nas escolas, e para que isso ocorra é necessário complementar a Lei Estadual 2282/17, garantindo assim aos professores que atuam nesse núcleo seus direitos.

A visão que tem quanto as mudanças produzidas no ambiente escolar após a implementação das PR é que elas ocorrem de forma individualizada. Cada escola apresenta pontos que se destacam, mas é comum haver mudanças de posturas e a diminuição dos conflitos. Além disso, ela aponta alguns problemas e demandas que podem ser trabalhadas com vistas a uma maior efetividade desta política pública: ausência da composição de uma equipe multidisciplinar para fortalecer os núcleos; problemas na consolidação das articulações em rede; faltam consolidar e buscar mais parcerias; atender as demandas das escolas em tempo hábil; priorizar a alimentação do sistema EPAZ e; respeitar o termo de colaboração entre TJAP, MP e SEED.

\section{Considerações Finais}

Ao longo desta pesquisa buscou-se investigar a aplicabilidade e os resultados das práticas restaurativas na mediação de conflitos no ambiente escolar em uma escola da rede estadual de ensino do município de Santana no Estado do Amapá. Isso propiciou reflexões que poderão nortear a prática educativa das escolas do Estado, com o propósito de rever seus conceitos em relação a forma de solucionar os conflitos e as práticas de violência vivenciadas no ambiente da escola, compreendendo que vai além da imposição da ordem, da disciplina e da punição.

Diante deste contexto, percebe-se a necessidade de políticas públicas eficazes que respondam aos anseios da sociedade, capazes de resolver a curto, médio e longo prazo as situações alarmantes que esse ambiente passou a ser permeado. E o Estado do Amapá, através das parcerias entre os poderes, estão buscando soluções para combater essas situações que se agravaram nas redes de ensino e que passou a não ser um problema só da escola, mas de todos aqueles que trabalham para a sociedade. Diante disso, criou-se a Lei 2.282/2017, que dispõe sobre a criação do Programa Educação para a Paz no Estado do 
Amapá, com o objetivo de promover a cultura de paz, prevenção da violência e a melhoria da convivência nas unidades educacionais, por meio de um conjunto de ações articuladas e transversais.

Os resultados desta pesquisa representam um alerta à Secretaria de Educação, diante da comprovada necessidade de continuidade de capacitação, assim como da importância do monitoramento dessa política, o qual é imprescindível para avaliar os avanços e entraves para que de fato a política pública se efetive, acrescentando que o sistema criado para monitorar os conflitos e violência na escola, ainda precisa ser melhor divulgado para que seja alimentado e assim possa ser mensurado a situação das escolas.

Quanto à Escola Estadual Ribamar Pestana, pode-se afirmar que a implementação das práticas restaurativas no ambiente escolar está proporcionando a Instituição resolver seus próprios conflitos, tirando lições de aprendizagem das situações conflituosas em interagindo com as famílias e com a comunidade. Ressalta-se que ainda há necessidade de melhorar o convívio no ambiente escolar, porém avançou-se muito nas relações interpessoais entre alunos versus alunos e professores versus alunos.

Percebeu-se que ainda é necessária uma maior divulgação dos princípios da justiça restaurativa na comunidade e no ambiente escolar, para que todos possam contribuir para a construção de uma sociedade mais democrática e que não seja restrito a alguns professores e sim a toda escola e seus segmentos, pois isto contribuirá de forma positiva na prevenção de novas ocorrências conflituosas. Outro fator que precisa ser assegurado pela escola é a inserção do Projeto de Práticas Restaurativas dentro do Projeto Político Pedagógico -PPP da escola, para de fato está fortalecido como uma das ações a serem executadas pela Instituição.

A Justiça Restaurativa e suas aplicações ao campo da educação através das práticas restaurativas representam melhorias no ambiente escolar, ainda de forma gradual, mas ergue-se a esperança na comunidade escolar de utilizar o diálogo para solucionar conflitos e agir como um fator de mudança social cujos efeitos podem ser sentidos nas comunidades beneficiadas pela escola em longo prazo. Reforça-se a necessidade de estudos futuros que analisem a política pública estabelecida no Estado do Amapá em que previne a violência e promove a paz em outros contextos escolares a fim de avaliar a política em todos os seus aspectos.

\section{Referências bibliográficas}

ABRAMOVAY, M. et al. Escola e violência. Brasília. DF: Unesco, 2002.

AMSTUTZ, Lorraine Stutzman; MULLET, Judy H. Disciplina Restaurativa para as escolas: responsabilidades e ambientes de cuidado mútuo. São Paulo: Palas Athena, 2012.

ARLÉ, Danielle de Guimarães Germano. A justiça restaurativa juvenil na comarca de Belo Horizonte - MG. In: JAYME, Fernando Gonzaga et al. Justiça restaurativa na prática: no compasso do Ciranda. Belo Horizonte, MG: Del Rey, 2018.

CHARLOT, Bernard. A violência na escola: como os sociólogos franceses abordam essa questão. Sociologias, v. 4, n. 8, 2002.

CECCON, Claudia et al. Conflitos na escola: modos de transformar. São Paulo, SP: CECIP; Imprensa oficial, 2010. 
COSTEllo, B.; WACHTEl, J.; WACHTEL, T. Manual de Práticas Restaurativas: para docentes, agentes disciplinadores e administradores de instituições de ensino. Instituto Internacional de Práticas Restaurativas. Bethlehem, Pensilvânia:[s.n], 2012.

EYNG, Ana Maria; GISI, Maria Lourdes; ENS, Romilda Teodora. Violências nas escolas e representações sociais: um diálogo necessário no cotidiano escolar. Revista Diálogo Educacional, v. 9, n. 28, p. 467-480, 2009.

EVANS, Katherine; VAANDERING, Dorothy. Justiça Restaurativa na educação: promover responsabilidade, cura e esperanças nas escolas. São Paulo, SP: Palas Athena, 2018.

LUDKE, M; ANDRÉ, M. Pesquisa em educação: abordagens qualitativas. São Paulo, SP: EPU, 1986.

MARTINS, Paulo Fernando de Melo; MARQUES, Julianne Freire; GUIMARÃES, Halyny Mendes. Educação e justiça restaurativa: os desafios na resolução de conflitos no ambiente escolar. Revista ESMAT, v. 8, n. 11, p. 11-28, 2017.

NUNES, Antonio Ozório. Como restaurar a paz nas escolas: um guia para educadores. São Paulo: Contexto, 2011.

SANTANA, Clóvis da Silva. Justiça Restaurativa na Escola: reflexos sobre a prevenção da violência e a indisciplina grave e na promoção da cultura de paz. 2011. 156f. Dissertação (Mestrado em Educação) - Universidade Estadual Paulista, Presidente Prudente, 2011.

YIN, Robert K. Estudo de Caso: planejamento e métodos. São Paulo: Bookman, 2015. 